National Water-Quality Assessment Program Transport of Anthropogenic and Natural Contaminants (TANC) to Public-Supply Wells

\title{
Simulations of Groundwater Flow and Particle Tracking Analysis in the Area Contributing Recharge to a Public-Supply Well near Tampa, Florida, 2002-05
}

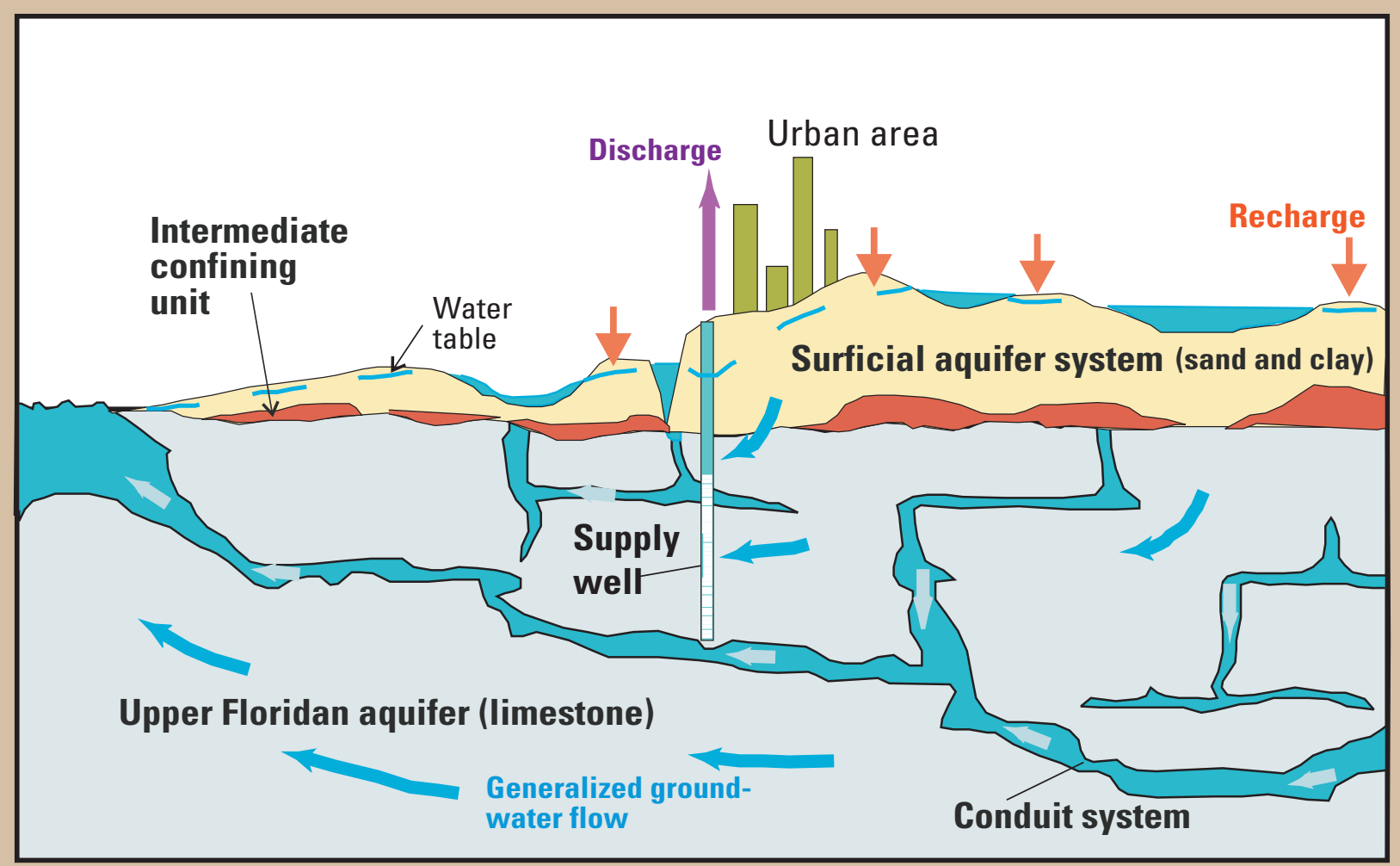

Scientific Investigations Report 2008-5231

U.S. Department of the Interior

U.S. Geological Survey 
